\section{Transformation in the Copper-Gold Alloy, $\mathrm{Cu}_{3} \mathrm{Au}$}

Oris. the papers of a theoretical nature read at the Spring Meeting of the Institute of Metals, that by Sykes and Evans on the transformation in the copper-gold alloy corresponding to the composition $\mathrm{Cu}_{3} \mathrm{Au}$ will probably be found by most readers to be of the greatest interest. The conclusions reached are as follows.

It has been shown that the general character of the transformation in $\mathrm{Cu}_{3} \mathrm{Au}$ is very similar to that predicted by W. L. Bragg and Williams. In particular, the transformation takes place continuously from the critical temperature to very low temperatures, and the equilibrium condition when produced after long annealing is displaced by a change in temperature, that is, the equilibrium is a dynamic one. The authors have found a large change in resistivity at the critical temperature, not previously established, which is in agreement with theory.

The simple hypothesis put forward in order to describe the relaxation to the equilibrium state is inadequate, and it is not yet possible to state whether a formula of the type :

$$
\frac{d \theta}{d t}=\frac{\theta-T}{\tau}
$$

is an accurate representation of the experimental facts, even if applied to a uniformly ordered structure. Further relaxation experiments on alloys ordered throughout on the same simple cubic lattice are desirable. We should expect a formula of the type

$$
\tau=A e^{w / K T}
$$

to hold in any case for relaxation at constant temperature, so that measurements of $\tau$ by both methods, that is, at constant temperature and during cooling, are desirable.

The marked difference in properties of the alloy containing nuclei as distinct from those ordered throughout on the same simple cubic lattice is of considerable interest, and previous work on trans. formations of this type should be reconsidered in view of these results.

The performance of different samples of the same alloy is accurately reproducible. This is perhaps remarkable in view of the large range of properties which can be obtained by heat treatment, and must be attributed to the fact that the transformation is an intracrystalline phenomenon almost independent of grain boundary effects.

\section{Educational Topics and Events}

London.-The degree of D.Sc. has been awarded to F. D. Miles (Imperial College-Royal College of Science) in regard to twenty-two works on physical chemistry, and the degree of D.Sc. (Engineering) to S. J. Davies, reader at King's College, in regard to six works on internal combustion engines and hydraulics, and seven conjoint papers.

ON August 31-September 12 this year, Harvard will celebrate the tercentenary of its foundation in 1636, when the general court of the Massachusetts Colony voted $£ 400$ toward "a schoale or colledge". First named "Newetowne", the name was changed to Harvard in 1639 when John Harvard, an immigrant
Puritan minister, bequeathed to the College, on his death, half of his estate $(£ 780)$ and 260 books. According to Science Service, of Washington, D.C. seventy-five of the world's leading men of science and other scholars will gather at Cambridge, Mass., in a conference seldom equalled in America in respect to distinguished speakers and the breadth of subjects. No less than fourteen Nobel Prize winners will be among those giving addresses ; they include Albert Einstein (physics), United States; Niels Bohr (physics), Denmark; Hans Fischer (chemistry), Germany; Arthur H. Compton (physics), United States ; Sir Frederick Gowland Hopkins (physiology and medicine), England; Robert A. Millikan (physics), United States; Friedrich Bergius (chemistry), Germany; August Krogh (physiology and medicine), Denmark; The Svedberg (chemistry), Sweden; Otto Warburg (physiology and medicine), Germany; Karl Landsteiner (physiology and medicine), United States; Hans Spemann (physiology and medicine), Germany; E. D. Adrian (physiology and medicine), England; and Werner Heisenberg (physics), Germany. Symposia will be held upon recent investigations in mathematics, astronomy, physics, chemistry, geology and biology, and also on broader problems such as "Factors Determining Human Behavior", "Authority and the Individual" and "Independence, Convergence and Borrowing in Institutions, Thought and Art", which will draw upon the social sciences and humanities.

The Carnegie Trust for the Universities of Scotland has published this year, in its thirty-fourth annual report, particulars of its seventh quinquennial allocation, covering the period $1936-40$, of grants to universities and other institutions for teaching and research. The grants amount in the aggregate to $£ 257,300$ for the whole period. This represents about half the Trust's income, the other half being devoted to assistance in payment of class fees of students. Of the $£ 30,000$ allocated for grants during the quinquennium to institutions other than universities, one half goes to the Royal Technical College, Glasgow, Robert Gordon's Colleges, Aberdeen, and the Heriot-Watt College, Edinburgh. The three agricultural colleges at those places, the Rowett and Macaulay research institutes at Aberdeen, the Veterinary Colleges at Glasgow and Edinburgh, St. Mungo's College, Glasgow, and the School of Medicine of the Royal Colleges in Edinburgh all come in for grants of $£ 1,000$ or more. The allocation was based on recommendations prepared after exhaustive inquiries by a Committee of Visitation. This quinquennial stocktaking and comprehensive review of the needs of the country in the field of higher education and research greatly enhance the importance of the Trust's services. Appended to the report are speeches broadcast in celebration of the first centenary of Andrew Carnegie's birth.

Applicatrons for Ramsay Memorial fellowships for chemical research, one of which will be limited to candidates educated in Glasgow, will be considered by the Ramsay Memorial Fellowship Trustees in June. The value of each fellowship will be $£ 250$ per annum, to which may be added a grant for expenses

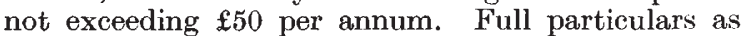
to the conditions of the awards are obtainable from the Secretary of the Ramsay Memorial Fellowships Trust, University College, London (Gower Street, W.C.1). 